\title{
Influence of L1 Properties and Proficiency on the Acquisition of Gender Agreement
}

\author{
Pierre-Luc Paquet \\ University of Guanajuato \\ Correspondence concerning this article should be addressed to Pierre-Luc Paquet, Universidad de \\ Guanajuato, Calzada de Guadalupe S/N, Colonia, Centro, C.P: 36000, Guanajuato, Mexico.. E-mail: \\ pierreluc.paquet@gmail.com
}

\begin{abstract}
This research investigates the influence of L1 properties and proficiency level on the acquisition of the Spanish gender agreement system. French and English-speaking learners of Spanish participated in the study. Subjects were divided into four different groups considering their L1 (French and English) and their proficiency level (intermediate and advanced). Subjects completed three different tasks: an untimed grammaticality judgment (UGJT) to measure learners' explicit knowledge, an elicited oral imitation (EOI) and an eye-tracking to assess their implicit knowledge of the Spanish gender agreement system. From this multi-tiered methodology, this research project aimed to examine whether L1 properties and proficiency level influence learners' explicit and implicit knowledge of the Spanish gender agreement. The results from the UGJT suggest that both French and English learners can notice nounadjective discord. As for the EOI and eye-tracking tasks, only the French advanced learners clearly demonstrated integrated implicit knowledge of gender agreement. Therefore, based on these results, we can imply that implicit knowledge of gender agreement is acquired later and that L1 properties influence this whole process, even at an advanced proficiency level.
\end{abstract}

Keywords: grammatical gender, adjective agreement, L2 Spanish, transfer, proficiency level, explicit knowledge, implicit knowledge, eye-tracking

\section{Influence of L1 Properties and Proficiency on the Acquisition of Gender Agreement}

The acquisition of morpho-syntactic features in a second language is often problematic, even for learners with advanced proficiency level (Bruhn de Garavito \& White, 2002; White, Valenzuela, KozlowskaMacgregor \& Leung, 2004; Keating, 2009; Foucart \& Frenck-Mestre, 2011). The development of an L2 can largely be affected by transfer, a general term used to explain the influence of an acquired language in the development of a new one (Gass \& Selinker, 1983; Odlin, 1989; Jarvis \& Pavlenko, 2008). It has been suggested that, when there is a similarity between two languages, learners can acquire a given structure without too much confusion by means of transfer (Sabourin, Stowe \& De Haan, 2006; Ellis, Conradie \& Huddlestone, 2012; Alhawary, 2005; 2009). Typological similarity and source language proficiency are known to influence transfer processes of any kind (Ringbom, 2007). However, it remains a methodological challenge to identify the extent to which transfer and proficiency level influence acquisition.

An area that has been widely explored in the field of morpho-syntax acquisition is L2 gender agreement (e.g., Sagarra \& Herschensohn, 2011; Montrul, de la Fuente, Davidson \& Foote, 2013, Hopp, 2016), a topic of great interest since it is a complex and ambiguous feature, which proves itself to be difficult whether or not L1 and L2 grammars differ. To investigate gender agreement, some studies have employed offline techniques to measure grammatical knowledge, such as grammaticality judgment task for comprehension and oral errors for production (White et al., 2004; Judy, Guijarro-Fuentes \& Rothman, 2008; Montrul, Foote \& Perpiñán, 2008; Alarcón, 2011). Other studies have used online techniques to measure implicit knowledge in real time, such as eye-tracking and event-related potentials (Keating, 2009; Tokowicz \& MacWhinney, 2005; Bañón, Fiorentino \& Gabriele, 2014). However, few studies have considered combining various tasks to tap into the acquisition of both explicit and implicit knowledge of gender agreement.

In this study, we investigate the influence of L1 
properties and proficiency level on the acquisition of explicit and implicit knowledge of the Spanish gender agreement system. French and English-speaking learners of Spanish participated in this research project. For their part, the underlying gender system in the French language has a direct counterpart in Spanish. In contrast, English has no concord on adjectives, making these two ideal cases to test the influence of transfer at different proficiency levels on the acquisition of this feature. Using a set of tasks ranging from an online receptive reading task (eyetracking) to an expressive task (elicited oral imitation) and an offline receptive task (untimed grammaticality judgment), this research project intends to extensively examine the influence of learners' L1 properties and proficiency level on the acquisition of both explicit and implicit knowledge of gender agreement.

\section{Crosslinguistic Influence}

Generally speaking, the notion of crosslinguistic influence can be summarised as the, "influence resulting from similarities and differences between target language and any other language that has been previously (and perhaps imperfectly) acquired" (Odlin, 1989, p. 27). Depending on learner-related factors, such as language proficiency and typology, prior knowledge will have more or less influence on the learner's receptive and expressive competence of the L2. Furthermore, the interaction between different language systems in a learner's mind may either help them understand or produce the L2 or not. Recently, Ringbom (2007) brought forward a new position in characterizing transfer in three different levels: 'item' for words, expressions, morphemes and phonemes, 'procedural' for transfer of language functional categories and 'overall' for the combination of both item and procedural.

According to Ringbom (2007), in order for transfer to happen at the 'item' level, it depends on how learners perceive the similarities and the differences between their L1 and their L2. Learners make use of an oversimplification strategy, where they would perceive the L2 as equivalent to their L1 and apply the rule as such. Item transfer is mostly observed at the lower proficiency level. As for procedural transfer, we refer once again to learners' perception of the linguistic distance that exists between both languages. In other words, the influence of procedural transfer is positive when both language structures are linguistically similar, i.e., whose functional categories are similar but could also be negative if they differ from each other. Even though it is well established that positive transfer is far more difficult to measure (e.g., Falk \& Bardel, 2010), the present study attempts to examine positive procedural transfer of gender agreement from French-speaking learners of Spanish.

\section{Learning Gender Agreement}

According to Corbett (1991), the existence of gender is revealed by morpho-syntactic agreement. In Spanish, the target language of the present study, adjectives grammatically agree with nouns in gender and number (Real Academia Española, 2010; Bosque \& Demonte, 1999). In many cases, morpho-phonological properties of the noun can provide a cue to its gender, with nouns ending in - o (e.g., piso 'flat') belonging to the masculine and those ending in - a (e.g., casa 'house') to the feminine class, although there are exceptions to these rules (see Montrul et al., 2008). As for French, adjectives grammatically agree with nouns as in Spanish, i.e., the systems work similarly. Compared to gendered languages such as Spanish and French, English does not mark grammatical gender on either nouns or adjectives (e.g., white house). Because of the process of gender concord (Steele, 1978), the adjective changes its inflection in accordance with the noun's gender, which dictates the variability in the inflectional pattern of the adjective. Consequently, gender agreement is a mechanism that indicates the relations of different linguistic categories in a sentence. While gender assignment is a lexical property of nouns, gender marking on adjectives is a derivative property that depends on the noun they modify. The principle that adjectives must be marked for the gender of the noun they are associated with is known as 'gender agreement'.

For morpho-syntactic gender agreement, many studies using online receptive tasks, such as eyetracking and event-related potentials, reveal that sensitivity to agreement violations correlates with the presence of grammatical gender marking in the learners' L1 (e.g., Bond, Gabriele, Fiorentino \& Bañón, 2011; Foucart \& Frenck-Mestre, 2011), as well as of learners' proficiency (Keating, 2009; Sagarra \& Herschenhohn, 2011; 2013; Gabriele, Fiorentino \& Bañón, 2013). Moreover, according to Morales et al. (2015), learners whose L1 encodes grammatical gender can come to use gender marking with a high level of accuracy at intermediate proficiency levels. To the contrary, some studies indicate that even highly advanced L2 learners who speak a genderless L1 still struggle with gender agreement on determiners, even for highly familiar L2 nouns (Lew-Williams \& Fernald, 2010; Grüter, Lew-Williams \& Fernald, 2012). Given this, it would appear that gender agreement is a feature acquired later in the acquisition process (Foucart \& Frenck- Mestre, 2011; Judy et al., 2008; Montrul et al., 2013). Regarding studies using offline 
receptive tasks, such as grammaticality judgment and sentence completion, they observe similar phenomena (Sabourin et al., 2006; Ellis et al., 2012). In other words, the presence of a gender system in the learners' $\mathrm{L} 1$ presents itself as being beneficial in the acquisition of such a feature.

While findings from some studies using oral expressive tasks are in keeping with the tendencies observed in the previously mentioned research (Alhawary, 2005; 2009; Dewaele \& Véronique, 2000; 2001; Barting, 2000), other research points towards a lesser influence of L1 properties in acquiring gender agreement (Bruhn de Garavito \& White, 2002; White et al., 2004). As the latter research stated, even though learners speak a gendered language, they still make gender concord errors at a frequency similar to their genderless language counterparts. With these contradictions in mind, the current study sought to explore this area further, putting forward an experiment combining different tasks, which allow for in-depth observations of the influence of L1 properties and proficiency level on the acquisition of gender agreement.

\section{The Present Study}

Most research observing the acquisition of gender agreement in an L2 indicate that L1 properties play a major role in the process (Sabourin et al., 2006; Ellis et al., 2012; Foucart \& Frenck-Mestre, 2011). However, most studies are either offline or online and focus solely on advanced proficiency learners. Additionally, the majority of these research projects did not take into account either type of linguistic knowledge assessed (explicit or implicit) or multiple L2 learners' proficiency level. The present study explored the extent to which acquiring explicit and implicit knowledge of gender agreement, exemplified by nounadjective concord, can be influenced by learners' L1 properties and proficiency level. Furthermore, Sagarra \& Herschensohn $(2011 ; 2013)$ recommended that future research use a combination of different tests. For this reason, we employed an online receptive reading task (eye-tracking experiment) and an offline receptive task (untimed grammaticality judgment task), and an expressive task (elicited oral imitation test) to investigate the following research questions:

1. Do L1 properties affect the development of learners' explicit and implicit knowledge of noun-adjective agreement?

The prediction for the first research question, whether L1 properties affect the development of learners' knowledge of gender concord, is that French speakers learners of Spanish will demonstrate sensitivity to gender agreement violations, whereas
English speaking learners of Spanish will not (for both explicit and implicit measures). This prediction follows Ringbom's (2007) procedural transfer, which assumes that syntactic processing in L2 is affected by the similarity of syntactic rules in L1 and L2.

2. Does L2 proficiency affect the acquisition process of noun-adjective gender agreement? Is there a difference between the intermediate and the advanced participants?

The second research question examines whether there is a difference between the intermediate and advanced learners when it comes to acquiring explicit and implicit knowledge of Spanish gender agreement. We hypothesize that advanced learners will be more sensitive to gender concord than the intermediate learners, in both the explicit and implicit measures. We base our prediction on previous research, which determined that gender agreement is a syntactic feature acquired late in the acquisition process (LewWilliams \& Fernald, 2010; Grüter et al., 2012; Foucart \& Frenck- Mestre, 2011; Judy et al., 2008; Montrul et al., 2013).

3. If taken together, do L1 properties in combination with proficiency level affect the types of knowledge acquired (explicit and implicit) to different extents?

The third research question focuses on examining to what extent learners' L1 properties and proficiency level, taken together, affect the acquisition of Spanish gender agreement. More specifically, we observe whether the differences between our four groups of learners, divided in terms of L1 properties and proficiency level, influence the types of knowledge expressed, namely explicit and implicit knowledge. The fact that it is well established that explicit and implicit knowledge are not accessed the same way leads us to suggest that there will be a difference between each group and their difficulties. Furthermore, additional research into crosslinguistic influence suggests that L1 properties are potentially more influential at the initial stages of acquisition (Odlin \& Jarvis, 2004; Jarvis \& Pavlenko, 2008). Consequently, we predict that the influence of L1 properties will stabilize at an advanced proficiency level.

\section{Materials and Methods}

A between-subjects design was employed to explore the influence of L1 properties and proficiency level in the development of explicit and implicit knowledge of grammatical gender agreement in L2 Spanish. Number agreement was kept constant, whereas gender was manipulated by using feminine and masculine 
patterns marked on nouns and adjectives within every experimental item. Explicit knowledge was measured through an untimed grammaticality judgment task (UGJT), whereas implicit knowledge was assessed through both an eye-tracking experiment and an elicited oral imitation test (EOI).

\section{Participants}

Twenty-three English and twenty French speaking learners of Spanish participated in the study. They were first asked to complete a placement test in order to classify them into one of the four groups: Englishintermediate $(n=11)$, English-advanced $(n=12)$, Frenchintermediate $(n=10)$ and French-advanced $(n=10)$. Participants who had learned and/or were previously exposed to any other L2s with grammatical gender were excluded from the study. Given the linguistic context of Canada, English-speaking Canadians were not considered for participation because of their probable active or passive knowledge of the French language. For that reason, the English-speaking subjects were all undergraduate students at a college in the northeast of the United States. The English participants included 10 males and 13 females. As for the French-speaking subjects, they were all enrolled in a postsecondary education program at different institutions in the province of Quebec in Canada. The French participants included 4 males and 16 females. Finally, for their data to be included in the results, all participants needed to complete all tasks, which were divided into two different sessions. Table 1 specifically illustrates the age range, number of Spanish courses completed and length of immersion in a Spanishspeaking country.

\section{Study Design}

The materials for the three tasks consisted of 24 sentences involving noun-adjective gender agreement, half of which were grammatical (i.e., the noun and modifying adjective agreed in gender) and half were ungrammatical (i.e., the noun and modifying adjective did not agree in gender). We also considered noun gender and linear distance in an attempt to diminish task effect. However, the present study highlights grammaticality, which should suffice to answer the research questions. Noun gender (masculine vs. feminine) was matched across conditions, whereas linear distance between the noun and its agreeing adjective was organized into three levels (see Table 2). The experimental items followed the same syntactic structure in all three experiments to complete. In each task, the 24 experimental items were mixed with 24 filler sentences that tested other aspects of grammar (tense, number agreement and verb conjugation).

The nouns and the adjectives used in this study were rigorously selected. First, all experimental nouns and adjectives ended in the suffixes commonly associated with gender $(-\mathrm{o}$ for masculine and $-\mathrm{a}$ for feminine). This was done to ensure that the emphasis was on gender agreement, not assignment. Errors in gender agreement are more salient when gender is marked morphologically on nouns and adjectives. Second, in order to eliminate confounding effects, we only used grammatical gender leaving semantic gender aside. Third, to ensure that the results were not influenced by unfamiliar words, all nouns $(n=55)$ and adjectives $(n=47)$ were selected from the benchmarks for beginners (A1-A2) of the Plan Curricular del Instituto Cervantes (2006). As shown in Table 2, we

Table 1

Background Information for the L2 Learners of Spanish

\begin{tabular}{|c|c|c|c|}
\hline Group & Age range & $\begin{array}{l}\text { Number of Spanish } \\
\text { courses completed }\end{array}$ & $\begin{array}{c}\text { Length of immersion in a } \\
\text { Hispanic country }\end{array}$ \\
\hline \multicolumn{4}{|l|}{ English intermediate $(n=11)$} \\
\hline Mean & 18.64 & 3.36 & 0.55 \\
\hline Range & $18-20$ & $0-4$ & $0-6$ \\
\hline$S D$ & 0.67 & 1.21 & 1.81 \\
\hline \multicolumn{4}{|l|}{ English advanced $(n=12)$} \\
\hline Mean & 20.08 & 4.17 & 2.75 \\
\hline Range & $18-22$ & $3-7$ & $0-12$ \\
\hline$S D$ & 1.16 & 1.03 & 4.56 \\
\hline \multicolumn{4}{|l|}{ French intermediate $(n=10)$} \\
\hline Mean & 32.6 & 0.9 & 0.70 \\
\hline Range & $17-64$ & $0-5$ & $0-5$ \\
\hline$S D$ & 15.73 & 1.91 & 1.64 \\
\hline \multicolumn{4}{|l|}{ French advanced $(n=10)$} \\
\hline Mean & 40.00 & 0.90 & 15.4 \\
\hline Range & $29-71$ & $0-4$ & $0-84$ \\
\hline$S D$ & 15.92 & 1.52 & 25.78 \\
\hline
\end{tabular}


controlled for terminal morphology, type of gender and word familiarity. However, creating 24 sentences per experiment constrained us to recycle experimental nouns and adjectives.

These different categories allowed learners' competence on both grammatical and ungrammatical sentences to be tested. All of the sentences were eight to twelve words long, so that processing demands would not cause longer sentences to be rejected or misunderstood.

\section{Procedure}

During the first session, participants first completed a screening test (placement test) in order to classify them in the right group. Afterwards, they performed an elicited oral imitation test (EOI) and an untimed grammaticality judgment task (UGJT). This session lasted approximately 90 minutes per participant. The second session took place two to three weeks later, where subjects participated in an eyetracking experiment, for approximately 45 minutes. As Sagarra \& Herschensohn (2011) suggested, we should have gone from the most implicit to the most explicit measure so that the latter did not bias the implicit processes of the former. Because of technical difficulties and availability of the eye-tracking device, we were unable to replicate this suggestion. However, we believe that the number of weeks between sessions was enough to control the learners' awareness of the focus of the study.

First session: Elicited oral imitation and untimed grammaticality judgment task. The EOI was designed to investigate learners' implicit knowledge of the Spanish gender agreement system within a semi-controlled expressive task. To date, this experiment is considered to be one of the most reliable tasks to measure implicit/intuitive L2 knowledge
(Erlam, 2006; 2009; Zhang, 2015). The EOI required participants to listen to a sentence in Spanish, to answer a yes or no comprehension question, which served as distraction, and then to reconstruct the sentence in the best Spanish possible. Each experimental item included a noun-adjective gender agreement. As previously mentioned, half the sentences were grammatical and half contained a noun-adjective gender discord. The EOI is reconstructive in nature and not rote repetition. Thus, we expected speakers who had internalized implicit knowledge of the target structure to spontaneously correct ungrammatical items. One point was allotted when the noun-adjective agreement was well reconstructed and no point when reconstructed otherwise.

The second experiment, UGJT, was designed to investigate learners' explicit knowledge of the Spanish gender agreement system through a receptive offline task. Since the UGJT required learners to focus on form and was not time constrained, it is considered a measure of explicit knowledge (Godfroid et al., 2015; Vafaee, Suzuki \& Kachisnke, 2017). In this experiment, participants read Spanish sentences silently on a computer screen, then decided whether each sentence was correct or incorrect and finally, if judged incorrect, indicated the source of the error. Subjects were allotted one point for identifying grammatical sentences as correct or ungrammatical ones as incorrect including identifying the error.

Second session: Eye-tracking experiment. Based widely on the recommendations of Keating (2009) and those of Roberts \& Siyanova-Chanturia (2013), the eye-tracking experiment was designed to investigate learners' implicit knowledge of the Spanish gender agreement system by means of an online receptive task. While reading, participants' eye-movements were recorded with an EyeTechSensor tracking device designed by PerTech. Viewing was binocular, with eye

Table 2

Experimental Items

3a) La comida de la cocinera está preparada con poca sal. 'The cook's food is prepared with little salt'

3b) La fiesta de mi amiga fue *divertido e impresionante. 'My friend's party was fun and impressive.' 
movement recorded from the right eye. The apparatus was interfaced with a PC that controlled stimulus display and data storage. The sentences were presented individually on a 17 -inch monitor. Sentences appeared in a single line in black against a light gray background using normal uppercase and lowercase letters.

Before each Spanish sentence, subjects were asked to fix a target that occupied the position of the sentence-initial character. They were instructed to look at the fixation target while pressing the 'Advance' button to display the sentence. Participants were asked to read the Spanish sentences for meaning and to indicate whether the subsequent sentence (written in the subjects' L1) expressed the same general idea as the Spanish sentence by pressing YES or NO. This check for meaning served as a distractor from the possible ungrammaticality of the target item.

Although eye movements were recorded on every word in each sentence, analyses were limited to data obtained from three different measures: Total reading time and time allotted to the regions of interest (ROI) 'adjective' (in milliseconds), and the regressions to the controller noun (in percentage of probability). This study examined if there were differences in the data regarding the learners' reading of the grammatical and the ungrammatical sentences. The equipment setup and calibration, combined with the online receptive task took approximately 45 minutes.

For comparability purposes, the EOI, the UGJT and the eye-tracking experiment contained the same number and type of sentences, but the content and noun-adjective combinations were different to avoid possible practice effects that would increase sensitivity to gender agreement violations.

\section{Results and Discussion}

This section presents the learners' performance on noun-adjective agreement in Spanish. As mentioned previously, data from this set of experiments allowed us to examine learners' explicit knowledge (UGJT) as well as implicit knowledge (EOI and eye-tracking) of the target feature.

\section{Experiment 1: Untimed Grammaticality Judgment Task}

The UGJT was aimed at examining the influence that L1 properties and proficiency level have on the acquisition of explicit knowledge. In order to make sure that we observed learners' explicit knowledge, we did not impose any time constraint and made sure that learners' attention was directed towards the linguistic forms.
As shown in Table 3, when isolating the L1 properties variable, the data showed no significant differences between the English-speaking and the French-speaking learners as both groups completed the UGJT with a high level of accuracy. However, there was a significant interaction between grammaticality and L1 properties with a significant level of $p=0.0022$.

To follow up on this interaction, logistic regressions were conducted separately for each group. The French-speaking learners were able to judge both the grammatical and the ungrammatical sentences with approximately the same level of accuracy (a difference of $3.63 \%$ ), whereas the English-speaking learners struggled significantly more with the ungrammatical sentences (a difference of 19.35\%). In other words, as shown in Table 3, the data analysis suggested that the English-speaking learners were less efficient at judging the ungrammatical than the grammatical items. These finding are in line with other research stating that L1 properties play a role when it comes to acquiring gender agreement in an L2 (Sabourin et al., 2006; Bond et al., 2011). It also supports Ringbom's (2007) procedural and inhibitive transfer hypothesis. According to this author, procedural transfer determines that L1 properties influence the acquisition process of syntactic features such as gender agreement, whereas inhibitive transfer occurs when the learner's L1 does not have specific structures of the target language and tends to be manifested as underuse or avoidance in production.

Table 3

UGJT results (considering $L 1$ properties)

(Standard errors appear in parentheses)

\begin{tabular}{lrrc} 
Groups & \multirow{2}{*}{ N } & \multicolumn{2}{c}{ Grammaticality } \\
& & Grammatical & Ungrammatical \\
\hline English speakers & 23 & $99.15(.62)$ & $79.80(.34)$ \\
French speakers & 20 & $97.74(.56)$ & $94.11(.42)$ \\
\hline
\end{tabular}

Regarding the learners' proficiency level, the logistic regression showed a certain tendency which came close to the level of significance of $p<0.05$, with a probability of $p=0.0585$. In other words, consistent with our prediction and the results of previous studies on the acquisition of gender agreement, advanced learners were more accurate at judging grammaticality, which suggests that this feature is acquired somewhat later in the acquisition process. We must mention that the data analysis did not show any significant interaction between proficiency and grammaticality. However, we acknowledge that the two groups were more accurate on grammatical than ungrammatical sentences, but the intermediate learners were substantially more affected by grammaticality (a difference of $14.1 \%$ ) than were the advanced learners (a difference of 6.6\%), 
as shown in Table 4.

Table 4

UGJT results (considering proficiency level)

(Standard errors appear in parentheses)

\begin{tabular}{lccc} 
Groups & $\mathrm{N}$ & \multicolumn{2}{c}{ Grammaticality } \\
& & Grammatical & Ungrammatical \\
\hline Intermediate & 21 & $97.35(.50)$ & $83.21(.37)$ \\
Advanced & 22 & $99.28(.67)$ & $92.72(.40)$ \\
\hline
\end{tabular}

As we consider the influence of L1 properties in combination with proficiency level, results did not reveal any significant differences between the four groups, with all of them scoring, on least square means, over $90 \%$ accuracy. However, after exploring the distribution of the learners' incorrect answers, the logistic regression showed a tendency between learners' L1 properties, proficiency level, and grammaticality, with a probability of $p=0.0992$. As shown in Table 5, both intermediate and advanced English-speaking learners of Spanish were less efficient at judging the ungrammatical items than the grammatical ones. As for the other two groups, who were intermediate and advanced French-speaking learners, the grammaticality of the Spanish sentences did not appear to influence their ability to judge them appropriately.

Table 5

UGJTresults (considering both between-subject variables)

(Standard errors appear in parentheses)

\begin{tabular}{lccc}
\hline Groups & $\mathrm{N}$ & \multicolumn{2}{c}{ Grammaticality } \\
& & Grammatical & Ungrammatical \\
\hline $\begin{array}{l}\text { English-speaking } \\
\text { Intermediate }\end{array}$ & 11 & $98.84(.81)$ & $66.18(.47)$ \\
English-speaking Advanced & 12 & $99.38(.90)$ & $88.85(.50)$ \\
French-speaking & 10 & $94.04(.58)$ & $92.62(.56)$ \\
Intermediate & 10 & $99.16(.94)$ & $95.32(.62)$ \\
French-speaking Advanced &
\end{tabular}

All data from the UGJT were subjected to fit test, more specifically to a variance estimate. With values in the area of equal to 1 for each group of learners, the statistical model appears to be a good fit for the experimental data.

Discussion of Experiment 1. With regard to explicit knowledge, assessed through the UGJT, results suggest that all four groups have the ability to accurately judge the grammaticality of the Spanish noun-adjective agreement. However, the fact that the English-speaking learners struggled more with the ungrammatical sentences than the grammatical ones shows that there exists a slight difference between the French and the English speakers and their explicit knowledge of the Spanish gender agreement system.
This suggests that typological similarities between French and Spanish help learners establish useful links on how noun-adjective agreement manifests itself in Spanish. As for the English-speaking L2 learners, the fact that they struggled more with the ungrammatical sentences could be explained as follows.

A possible explanation for this phenomenon could be that English speakers make use of an avoidance strategy. When they are uncertain about the grammaticality of the sentence, the English-speaking learners prefer not to identify the source of the error in the subsequent question. Therefore, were we to consider the preceding argument as a demonstration of learners' lower confidence level, English speakers learning Spanish may have been influenced by the proposed task. In order to examine the validity of this explanation, in a subsequent study, it would be of great interest to include a confidence rating judgment, which would allow us to compare the results of the UGJT to the confidence rating.

As for another explanation for this phenomenon, according to Godfroid et al. (2015), asking participants to identify the grammatical error pushes them to rely more on explicit and analyzed knowledge. Moreover, it has been suggested that ungrammatical sentences make higher demands on control and analysis than the grammatical ones (Bialystok, 1986). Taking these visions into consideration would suggest that the English-speaking learners exert less control over their explicit knowledge than their French counterparts. In other words, we could suggest that French-speaking learners have more control over their explicit knowledge than the English-speaking ones, which would be explained by the presence of an extensive gender system in their L1 properties.

To recap and summarize, two possible strands emerge to explain the observed differences between the manner in which the French and the English participants processed the ungrammatical sentences. Either learners' level of confidence or control over their explicit knowledge is the underlying explanation. The unifying account is one of Godfroid et al. (2015) who stated that, "whereas the presence of an ungrammatical element is sufficient evidence that a sentence is ungrammatical, the absence of an ungrammatical element is essentially a lack of evidence" (p. 289). In other words, the fact that the English participants struggled more with the ungrammatical sentences does not mean that they lack explicit knowledge of gender agreement. However, the fact that their French counterparts did not experience the same challenge towards judging grammaticality points to the presence of an extensive gender agreement system in their L1 properties, which would help them to demonstrate efficiency.

Experiment 2: Elicited Oral Imitation Test 
This task was conducted to investigate learners' implicit knowledge of the Spanish gender agreement system within a semi-controlled expressive task. Moreover, this second experiment aimed at examining whether L1 properties and proficiency level play a role when it comes to reconstructing Spanish sentences, which include a noun-adjective gender agreement.

Before we take a look at the analysis for the between-subject variables, it is important to mention that grammaticality revealed itself as significant, with a level of significance below 0.05 of $p<.0001$. The French-speaking as well as the English-speaking learners struggled more with the ungrammatical sentences than the grammatical ones. Moreover, regarding the influence of L1 properties in the development of implicit knowledge, the results from the EOI demonstrated that the French-speaking learners were more accurate at reconstructing nounadjective gender agreement than their English counterparts with a level of significance below 0.05 of $p=0.0146$.

As shown in Table 6, the French-speaking learners were more accurate at reconstructing ungrammatical items than their English counterparts. The $60.53 \%$ and $40.05 \%$ least square means respectively suggest that the test is reconstructive in nature and that both groups of learners have some implicit knowledge of gender agreement.

Table 6

EOI results (considering $L 1$ properties)

(Standard errors appear in parentheses)

\begin{tabular}{lccc}
\hline \multirow{2}{*}{ Groups } & \multirow{N}{c}{} & \multicolumn{2}{c}{ Grammaticality } \\
& & Grammatical & Ungrammatical \\
\hline English speakers & 23 & $67.61(.20)$ & $40.05(.20)$ \\
French speakers & 20 & $77.87(.24)$ & $60.53(.22$ \\
\hline
\end{tabular}

When considering the possible effect of proficiency on the acquisition of implicit knowledge of gender agreement, the statistical analysis demonstrated a significant difference between the intermediate and the advanced learners (below of 0.05 of $p=0.0077$ ). As shown in Table 7, the probability that the intermediate learners reconstruct the experimental items grammatically is significantly lower than for their advanced counterparts.

Even though the logistic regression did not reveal any significant interaction between proficiency level and grammaticality, it is worth mentioning thetendency towards significance between these variables, with a probability of $p=0.0808$. In other words, the logistic regressions allowed us to observe that intermediate learners were less likely to reconstruct items that included a noun-adjective gender discord than the advanced ones. Aligned with Erlam (2006), the fact that the intermediate learners were able to reconstruct $37.9 \%$ of the ungrammatical sentences show that they do have some implicit knowledge of Spanish gender agreement. However, it also demonstrates that nounadjective gender agreement is a syntactic feature acquired later in the L2 learning process (Montrul et al., 2008; Montrul, Davidson, de la Fuente \& Foote, 2014).

Table 7

EOI results (considering proficiency level)

(Standard errors appear in parentheses)

\begin{tabular}{lrrc} 
Groups & $\mathrm{N}$ & \multicolumn{2}{c}{ Grammaticality } \\
& & Grammatical & Ungrammatical \\
\hline Intermediate & 21 & $68.13(.21)$ & $37.89(.21)$ \\
Advanced & 22 & $77.46(.23)$ & $62.67(.21)$ \\
\hline
\end{tabular}

When examining the possible interaction between learners' L1 properties and proficiency level, it shows that the advanced French-speaking L2 learners were more accurate at reconstructing the Spanish sentences than any other group, especially the intermediate English speakers. As illustrated in Table 8, we can also observe that the intermediate French-speaking and the advanced English-speaking learners were able to complete the task with approximately the same accuracy. This observation could be interpreted as proof of the presence of crosslinguistic influence where French-speaking learners rely on their L1 properties of gender agreement.

Table 8

EOI results (considering both between-subject variables)

(Standard errors appear in parentheses)

\begin{tabular}{|c|c|c|c|}
\hline \multirow[t]{2}{*}{ Groups } & \multirow[t]{2}{*}{$\mathrm{N}$} & \multicolumn{2}{|c|}{ Grammaticality } \\
\hline & & Grammatical & Ungrammatical \\
\hline $\begin{array}{l}\text { English-speaking } \\
\text { Intermediate }\end{array}$ & 11 & $59.75(.40)$ & $30.17(.30)$ \\
\hline English-speaking Advanced & 12 & $74.59(.29)$ & $50.82(.26)$ \\
\hline $\begin{array}{l}\text { French-speaking } \\
\text { Intermediate }\end{array}$ & 10 & $46.28(.30)$ & $75.48(.32)$ \\
\hline French-speaking Advanced & 10 & $80.09(.35)$ & $73.18(.33)$ \\
\hline
\end{tabular}

All data from the EOI were subjected to fit test, more specifically to a variance estimate. With values in the area of equal to 1 for each group of learners, the statistical model also appears to be a good fit for this set of experimental data.

Discussion of Experiment 2. Regarding the acquisition of implicit knowledge within a semicontrolled expressive task, it was possible to observe that learners L1 properties as well as proficiency level have a certain impact in reconstructing noun-adjective gender agreement adequately. As described by the statistical analysis, results suggest that the French- 
speaking subjects were able to complete the task better and more accurately than the English-speaking ones. Moreover, results also demonstrate that advanced learners are more efficient than their intermediate counterparts. When taken the two between-subjects variables together, we can perceive that advanced French-speakers are, overall, more accurate than the other groups and that the intermediate French and the advanced English are similar.

The similarity between the intermediate French and the advanced English speakers may reflect the fact that, in general, the French-speaking learners are better able to rely on their overall experience with gender agreement; namely procedural transfer. In other words, given the fact that this abstract feature is represented in their L1, the French-speaking learners may successfully process the Spanish gender agreement system at a lower level of proficiency in comparison with the English-speaking learners.

\section{Experiment 3: Eye-tracking experiment}

This task was conducted to investigate learners' sensitivity to gender agreement discord within an online receptive reading experiment. According to Dussias (2010), the advantage of using an eye-tracking experiment is the possibility of watching subjects' sensitivity to grammatical discord as we register the eye-movement for every millisecond. This section will enumerate data from this experiment, considering three different measures: total reading time, time allotted to the region of interest (ROI) 'adjective' and finally, regression to the controller noun. Before we start analyzing the results, it should be pointed out that $37 \%$ of the data from the eye-tracking were excluded from the analysis due to technical difficulties.

In the eye-tracking experiment, grammaticality revealed itself as significant in the measure of ROI 'adjective' $(p=0.0015)$ and as a strong tendency in the total reading time $(p=0.0622)$. Regarding the influence of $L 1$ properties on the acquisition of gender agreement, none of the measures demonstrated any significant interaction between the learners L1 properties and grammaticality. Yet, there is an observable tendency between the French and English-speaking learners of Spanish, as shown in Table 9. It seems that the French-speaking subjects take more time in reading ungrammatical sentences than grammatical ones. As for the English-speaking learners, analysis did not show any difference between both conditions. In other words, this tendency $p=0.0783$ suggests that Frenchspeaking subjects could be more sensitive to gender discord than their English counterparts, which would suggest that they possess greater implicit knowledge of the Spanish gender agreement system.

Regarding the effect of proficiency level in the subjects' sensitivity to noun-adjective agreement, none of the three measures demonstrated a clear difference between the way intermediate and advanced speakers read the Spanish sentences. However, it appears that advanced learners spend more time in the ROI 'adjective' of the ungrammatical sentences than the grammatical ones. Furthermore, the probability of making a regression to the controller noun when the item is ungrammatical seems to be higher for advanced (difference of $6.01 \%$ ) than for intermediate learners (difference of $4.43 \%$ ). As shown in Table 10, a certain tendency between proficiency and grammaticality can be acknowledged. Data analyses, however, did not provide enough evidence for this interaction to be significant.

When examining the possible triple interaction between both between-subject variables and grammaticality, data analysis shows that the advanced French-speaking learners were significantly more sensitive to noun-adjective discord than any other groups as the total reading time suggests, with a level of significance of $p=0.0047$. Logistic regressions were then conducted separately for each group. As shown in Table 11, the advanced French-speaking learners took more time in reading the ungrammatical items than the grammatical ones, with a level of significance below 0.05 of $p=0.0003$. In addition, they spent more time in the ROI 'adjective' when the sentences included a gender discord, with a level of significance $p<.0001$. Finally, when observing the possible regressions to the controller noun, results suggest that the advanced French-speaking group tended to go back to the controller noun more often when the item was ungrammatical (a difference of $20.79 \%$ more), with a level of significance below 0.05 of $p=0.0032$. As for the other three groups, they did not appear to be sensitive to gender discord at this time. Consequently, findings from the eye-tracking experiment indicate that

Table 9

Eye-tracking experiment (considering L1 properties)

\begin{tabular}{|c|c|c|c|c|c|c|c|}
\hline \multicolumn{8}{|c|}{ (Standard errors appear in parentheses) } \\
\hline \multirow{2}{*}{ Groups } & \multirow{2}{*}{$\mathrm{N}$} & \multicolumn{3}{|c|}{ Total reading time (s.) } & \multicolumn{3}{|c|}{ Time allotted to ROI 'adjective' (s.) } \\
\hline & & G & UG & Diff. & G & UG & Diff. \\
\hline English speakers & 13 & $5.630(.45)$ & $5.745(.47)$ & 0.12 & $0.646(.06)$ & $0.628(.06)$ & -0.02 \\
\hline French speakers & 15 & $5.506(.37)$ & $6.180(.39)$ & 0.67 & $0.615(.05)$ & $0.796(.06)$ & 0.18 \\
\hline
\end{tabular}


Table 10

Eye-tracking experiment (considering proficiency level)

\begin{tabular}{|c|c|c|c|c|c|c|c|}
\hline \multicolumn{8}{|c|}{ (Standard errors appear in parentheses) } \\
\hline \multirow{2}{*}{ Groups } & \multirow{2}{*}{$\mathrm{N}$} & \multicolumn{3}{|c|}{ Total reading time (s.) } & \multicolumn{3}{|c|}{ Time allotted to ROI 'adjective' (s.) } \\
\hline & & $\mathrm{G}$ & UG & Diff. & $\mathrm{G}$ & UG & Diff. \\
\hline Intermediate & 12 & $\begin{array}{l}06.04 \\
(0.45)\end{array}$ & $\begin{array}{l}6.32 \\
(.47) \\
\end{array}$ & 0.28 & $\begin{array}{l}0.71 \\
(.06) \\
\end{array}$ & $\begin{array}{l}0.79 \\
(.06) \\
\end{array}$ & 0.08 \\
\hline Advanced & 16 & $\begin{array}{l}05.10 \\
(0.37)\end{array}$ & $\begin{array}{l}5.60 \\
(.40) \\
\end{array}$ & 0.50 & $\begin{array}{l}0.55 \\
(.05) \\
\end{array}$ & $\begin{array}{l}0.70 \\
(.05) \\
\end{array}$ & 0.15 \\
\hline
\end{tabular}

Table 11

Eye-tracking experiment (considering both between-subject variables)

\begin{tabular}{|c|c|c|c|c|c|c|c|}
\hline \multicolumn{8}{|c|}{ (Standard errors appear in parentheses) } \\
\hline \multirow{2}{*}{ Groups } & \multirow{2}{*}{$\mathrm{N}$} & \multicolumn{3}{|c|}{ Total reading time (s.) } & \multicolumn{3}{|c|}{ Time allotted to ROI 'adjective' (s.) } \\
\hline & & $\mathrm{G}$ & UG & Diff. & $\mathrm{G}$ & UG & Diff. \\
\hline English-speaking intermediate & 06 & $\begin{array}{l}5.92 \\
(.72)\end{array}$ & $\begin{array}{l}6.53 \\
(.74)\end{array}$ & 0.61 & $\begin{array}{l}0.72 \\
(.10)\end{array}$ & $\begin{array}{l}0.84 \\
(.10)\end{array}$ & 0.12 \\
\hline English-speaking advanced & 07 & $\begin{array}{l}5.40 \\
(.55)\end{array}$ & $\begin{array}{l}4.96 \\
(.59)\end{array}$ & -0.44 & $\begin{array}{l}0.57 \\
(.08)\end{array}$ & $\begin{array}{l}0.56 \\
(.07)\end{array}$ & -0.01 \\
\hline French-speaking intermediate & 06 & $\begin{array}{l}6.15 \\
(.55)\end{array}$ & $\begin{array}{l}6.12 \\
(.56)\end{array}$ & -0.03 & $\begin{array}{l}0.71 \\
(.08)\end{array}$ & $\begin{array}{l}0.75 \\
(.07)\end{array}$ & 0.04 \\
\hline French-speaking advanced & 09 & $\begin{array}{l}4.86 \\
(.49)\end{array}$ & $\begin{array}{l}6.24 \\
(.54)\end{array}$ & 01.38 & $\begin{array}{l}0.52 \\
(.06)\end{array}$ & $\begin{array}{l}0.85 \\
(.08)\end{array}$ & 0.33 \\
\hline
\end{tabular}

advanced French-speaking learners of Spanish were the only group sensitive to noun-adjective agreement discord, which suggest that they are the only ones to have well integrated implicit knowledge of gender agreement.

All data from the eye-tracking experiment were subjected to fit test, more specifically to a variance estimate. With values in the area of equal to 1 for each group of learners, the statistical model appears to be a good fit for the experimental data.

Discussion of Experiment 3. Regarding the acquisition of implicit knowledge within an online receptive experiment, the only group who showed sensitivity to noun-adjective agreement discrepancies was the advanced French-speaking learners of Spanish. As previously discussed, most research examining the influence of L1 properties on the acquisition of gender agreement concurs that the presence of a gender system in the learners' L1 favorably influence their level of acquisition (Foucart \& Frenck-Mestre, 2011; Bond et al., 2011). Moreover, the fact that the intermediate French-speaking learners did not show any sensitivity to noun-adjective discord allows us to postulate towards the idea that implicit knowledge of gender agreement is acquired late in the acquisition process, as others have already suggested (Keating, 2009; Foucart \& Frenck-Mestre, 2011; Judy et al., 2008; Montrul et al., 2013). This observation could be interpreted as proof of the presence of crosslinguistic influence where learners rely on their L1 properties of gender agreement; a phenomenon which may apply to learners of any stage of language development.

\section{General Discussion}

The goal of the present study was to examine the influence of L1 properties and of proficiency level on the acquisition of noun-adjective gender agreement across a variety of experimental tasks, including an expressive measure, as well as offline and online receptive reading measures, in groups of intermediate and advanced French and English-speaking learners of Spanish. A research design of this type was necessary in order to tease apart the acquisition of explicit and implicit knowledge. It is important to mention that, as DeKeyser (2009) pointed out, "often students will have considerable amounts of explicit knowledge about parts of the L2, but little or no competence, i.e., implicit, intuitive knowledge, of the same elements in the same L2" (p.124). This comment, together with the findings from the three experiments carried out in this research project, suggest that even though all of the participants exhibited a high level of explicit knowledge, it does not mean that the same representation will apply for implicit knowledge.

Regarding the first research question, which aimed at observing the influence of L1 properties on the acquisition of gender agreement, the results partially support our prediction that learners' L1 properties would affect the acquisition of the Spanish gender agreement system. Taking explicit knowledge into account, both French and English-speaking learners performed at a high level of accuracy. Indeed, even though the analyses suggest a difference in the way each group responded to the ungrammatical 
sentences, there were no significant differences in accuracy between subjects. Meanwhile, in terms of implicit knowledge, it appears that L1 properties affect learners' accuracy in the acquisition of gender agreement. To conclude, based on the interpretation of findings, it appears that L1 properties play a role when it comes to increasing the learners' level of confidence of difficult grammar elements, to reconstructing ungrammatical Spanish sentences and to being sensitive to agreement discord. In other words, L1 properties appear to affect the learners' knowledge of the Spanish gender agreement system.

As for the second research question, which focused on the effect of proficiency level, results partially support our prediction that learners' proficiency would affect the level of acquisition of the Spanish gender agreement system. Considering learners' explicit knowledge of gender agreement, both intermediate and advanced learners performed at a high level of accuracy. In fact, even though results appear to be slightly different in the way each group processed gender agreement, there were no significant differences in accuracy between the two groups' proficiency level. Concurrently, it appears that proficiency level partially affects learners' implicit knowledge. In the expressive task, the advanced learners were more accurate at reconstructing ungrammatical sentences than the intermediate ones. To conclude, based on the interpretation of findings, it appears that level of proficiency plays a role in regard to learners' implicit knowledge of the Spanish gender agreement system, taking into account results from the expressive task. Nevertheless, it would appear that we have insufficient evidence to demonstrate an influence of proficiency level since none of the measures from the eye-tracking allow us to examine a significant interaction between these variables.

The above findings are especially noteworthy in light of our third research question, which examined a combination of both between-subject variables. Taking L1 properties and proficiency level together, the three experiments included in the study indicate that the Spanish gender agreement system poses different problems depending on the types of knowledge assessed. The relatively high level of overall achievement in Spanish L2/L3 of all participants in the UGJT did not reflect the findings observed in the EOI, which was essentially used to assess the learners' implicit knowledge. As for the eye-tracking experiment, only the one group demonstrated sensitivity to gender discord, which suggest that implicit knowledge of gender agreement is normally acquired later in the acquisition process (Keating, 2009; Foucart \& FrenckMestre, 2011; Judy et al., 2008; Montrul et al., 2013; among others) and that L1 properties influence this whole process, even at an advanced proficiency level
(Sabourin et al., 2006; Ellis et al., 2012; Alhawary, $2005 ; 2009)$.

\section{Conclusion}

The contribution of the present study for research communities who investigate gender agreement is two-fold: shedding additional light on the influence of L1 properties and proficiency level on the acquisition of gender agreement and using a research design that taps into both explicit and implicit knowledge. Based on the findings of the present study, the difference between the French and the English speakers learning Spanish is best represented in the tasks measuring implicit knowledge, including both the EOI and the eye-tracking experiment. However, it is important to mention that acquiring gender agreement is not only influenced by L1 properties but also proficiency.

Furthermore, the unique methodology used in the form of an offline and an online receptive task, and an oral expressive test represents an innovation in terms of possible triangulation of data. Indeed, even though each task contained items that included the same sentence structure, the same number of words and the same accessible vocabulary, results allowed us to arrive at different perspectives of the same phenomenon, namely acquisition of gender agreement.

The results show that certain types of L2 knowledge may or may not be accessible during metalinguistic tasks and during real-time comprehension, depending on the levels of proficiency; and that this knowledge can be tapped into by different tasks to offer a more rounded picture of what "acquisition" means. (Roberts, 2013, p. 632).

Taking the above into account demonstrates the need for a multi-tiered methodology to best investigate the complex linguistic feature that is gender agreement. The present study is proof of that and future research should invest time and effort to maximize our understanding of second language acquisition of abstract features in order to better assist instructors and learners.

\section{References}

Alarcón, I. (2011). Spanish gender agreement under complete and incomplete acquisition: Early and late bilinguals' linguistic behavior within the noun phrase. Bilingualism: Language and Cognition, 14(3), 332-350. DOI: https://doi.org/10.1017/ S1366728910000222

Alhawary, M. T. (2005). L2 acquisition of Arabic 
morphosyntactic features: Temporary or permanent impairment. Perspectives on Arabic linguistics, 17(18), 273-312.

Alhawary, M.T.(2009). Speech processing prerequisites or L1 transfer? Evidence from English and French L2 learners of Arabic. Foreign Language Annals, 42(2), 367-390. DOI: 10.1111/j.1944-9720.2009.01025.x

Bañón, J. A., Fiorentino, R., \& Gabriele, A. (2014). Morphosyntactic processing in advanced second language (L2) learners: An event-related potential investigation of the effects of L1-L2 similarity and structural distance. Second Language Research, 30(3), 275-306. DOI: https://doi. org/10.1177/0267658313515671

Barting, I. (2000). Gender agreement in L2 French: Preadvanced vs advanced learners*. Studia Lingüística, 54(2), 225-237. DOI: 10.1111/1467-9582.00062

Bialystok, E. (1986). Factors in the Growth of Linguistic Awareness. Child development, 57(2), 498-510. DOI: 10.2307/1130604

Bond, K., Gabriele, A., Fiorentino, R., \& Bañón, J. A. (2011). Individual differences and the role of the L1 in L2 processing: An ERP investigation. In J. Herschensohn \& D. Tanner (Eds.), $11^{\text {th }}$ Generative Approaches to Second Language Acquisition Conference (pp. 17- 29). Seattle, WA: University of Washington.

Bosque, I., \& Demonte, V. (1999). Gramática descriptiva de la lengua española: Entre la oración y el discurso [Descriptive grammar of the Spanish language: In between sentence and discourse]. Madrid, Spain: Espasa Calpe, S.A.

Bruhn de Garavito, J., \& White, L. (2002). The L2 acquisition of Spanish DPs. The status of grammatical features. In A. T. Pérez-Leroux \& J. Liceras (Eds.), The acquisition of Spanish morphosyntax: The L1/L2 connection ( $1^{\text {st }}$ ed., pp. 151-176). Dordrecht, Netherlands: Wolters Kluwer.

Corbett, G. (1991). Gender. Cambridge, UK: Cambridge University Press.

DeKeyser, R. M. (2009). Cognitive-psychological processes in second language learning. In $\mathrm{M}$. H. Long \& C. J. Doughty (Eds.), The handbook of langage teaching (pp. 119-132). Oxford, UK: WileyBlackwell.

Dewaele, J-M., \& Véronique, D. (2000). Relating gender errors to morphosyntax and lexicon in advanced French interlanguage. Studia Linguistica, 54(2), 212-224. DOI: 10.1111/1467-9582.00061

Dewaele, J-M., \& Véronique, D. (2001). Gender assignment and gender agreement in advanced French interlanguage: A cross-sectional study. Bilingualism: Language and Cognition, 4(3), 275-296. DOI: https://doi.org/10.1017/S136672890100044X

Dussias, P. E. (2010). Uses of eye-tracking data in second language sentence processing research.
Annual Review of Applied Linguistics, 30, 149-166. DOI: https://doi.org/10.1017/ S026719051000005X

Ellis, C., Conradie, S., \& Huddlestone, K. (2012). The acquisition of grammatical gender in L2 German by learners with Afrikaans, English or Italian as their L1. Stellenbow Papers in Linguistics, 41, 17-27.

Erlam, R. (2006). Elicited imitation as a measure of L2 implicit knowledge: An empirical validation study. Applied linguistics, 27(3), 464-491. DOI: https://doi. org/10.1093/applin/aml001

Erlam, R. (2009). The elicited oral imitation test as a measure of implicit knowledge. In R. Ellis et al. (Eds.), Implicit and Explicit knowledge in second language learning, testing and teaching (pp. 65-93). Bristol, UK: Multilingual Matters.

Falk, Y., \& Bardel,C. (2010). The study of the background languages in third language acquisition. The state of the art. IRAL, 48, 185-219. DOI: https://doi. org/10.1515/iral.2010.009

Foucart, A., \& Frenck-Mestre, C. (2011). Grammatical gender processing in L2: Electrophysiological evidence of the effect of L1-L2 syntactic similarity. Bilingualism: Language and Cognition, 14(3), 379-99. DOI: https://doi.org/10.1017/S136672891000012X

Gabriele, A., Fiorentino, R., \& Bañón, J. A. (2013). Examining second language development using event-related potentials: A cross-sectional study on the processing of gender and number agreement. Linguistic Approaches to Bilingualism, 3(2), 213-232. DOI: http://dx.doi.org/10.1075/lab.3.2.04gab

Gass, S., \& Selinker, L. (1993). Language transfer in language learning. Amsterdam, Reino de los Países Bajos, Netherlands: John Benjamins Publishing Company.

Godfroid, A., Loewen, S., Jung, S., Park, J., Gass, S., \& Ellis, R. (2015). Timed and untimed grammaticality judgments measure distinct types of knowledge: Evidence from eye-movement patterns. Studies in Second Language Acquisition, 37(2), 269-297. DOI: https://doi.org/10.1017/S0272263114000850

Grüter, T., Lew-Williams, C., \& Fernald, A. (2012). Grammatical gender in L2: A production or a real-time processing problem? Second Language Research, 28(2), 191-215. DOI: https://doi. org/10.1177/0267658312437990

Hopp, H. (2016). Learning (not) to predict: Grammatical gender processing in adult L2 acquisition. Second Language Research, 32, 277-307.

Instituto Cervantes. (2006). Plan curricular del Instituto Cervantes: Niveles de referencia para el español: $A 1 / A 2$. [Cervantes Institute Curriculum Plan: Benchmarks for Spanish A1/A2]. Madrid, Spain: Biblioteca Nueva.

Jarvis, S., \& Pavlenko, A. (2008). Crosslinguistic influence in language and cognition. New York, NY \& London, UK: Routledge. 
Judy, T., Guijarro-Fuentes, P., \& Rothman, J. (2008). Adult accessibility to L2 representational features: Evidence from the Spanish DP. In M. Bowles, R. Foote, S. Perpiñán \& R. Bhatt (Eds.), Selected proceedings of Second Language Research Forum (pp. 1-21). Somerville, MA: Proceedings Project.

Keating, G. D. (2009). Sensitivity to violations of gender agreement in native and nonnative Spanish: An eyemovement investigation. Language Learning, 53(3), 503-535. DOI: 10.1111/j.1467-9922.2009.00516.x

Lew-Williams, C. \& Fernald, A. (2010). Real-time processing of gender-marked articles by native and non-native Spanish speakers. Journal of Memory and Language, 63(4), 447-64. DOI: https://doi. org/10.1016/j.jml.2010.07.003

Montrul, S., Foote, R., \& Perpiñán, S. (2008). Gender agreement in adult second language learners and Spanish heritage speakers: The effects of age and context of acquisition. Language Learning, 58(3), 503-553. DOI: 10.1111/j.1467-9922.2008.00449.x

Montrul, S., de la Fuente, I., Davidson, J., \& Foote, R. (2013). The role of experience in the acquisition and production of diminutives and gender in Spanish: Evidence from L2 learners and heritage speakers. Second Language Research, 29(1), 87-118. DOI: https://doi.org/10.1177/0267658312458268

Montrul, S., Davidson, J., de la Fuente, I., \& Foote, R. (2014). Early language experience facilitates the processing of gender agreement in Spanish heritage speakers. Bilingualism: Language and Cognition, 17(1), 118-138. DOI: https://doi.org/10.1017/ S1366728913000114

Morales, L., Paolieri, D., Dussias, P. E., Valdés Kroff, J. R., Gerfen, C., \& Bajo, M. T. (2016). The gender congruency effect during bilingual spoken-word recognition. Bilingualism: Language and Cognition, 19(2), 294-310. DOI: https://doi.org/10.1017/ S1366728915000176

Odlin, T. (1989). Language transfer: Cross-linguistic influence in language learning. Cambridge, UK: Cambridge University Press.

Odlin, T., \& Jarvis, S. (2004). Same source, different outcomes: A study of Swedish influence on the acquisition of English in Finland. International Journal of Multilingualism, 1(2), 123-140. DOI: https://doi.org/10.1080/14790710408668183

Real Academia Española. (2010). Nueva gramática de la lengua española manual [New handbook of the Spanish grammar]. Barcelona, Spain: Espasa.

Ringbom, H. (2007). Cross-linguistic similarity in foreign language learning: Comprehension, learning and production. Clevedon, UK: Multilingual Matters.

Roberts, L. (2013). Processing of gender and number agreement in late Spanish bilinguals: A commentary on Sagarra and Herschensohn. The International Journal of Bilingualism, 17(5), 628-633. DOI: https:// doi.org/10.1177/1367006911435693

Roberts, L., \& Siyanova-Chanturia, A. (2013). Using eye-tracking to investigate topics in L2 acquisition and L2 processing. Studies in Second Language Acquisition, 35(2), 213-235. DOI: https://doi. org/10.1017/S0272263112000861

Sabourin, L., Stowe, L. A., \& De Haan, G. J. (2006). Transfer effects in learning a second language grammatical gender system. Second Language Research, 22(1), 1-29. DOI: https://doi. org/10.1191/0267658306sr259oa

Sagarra, N., \& Herschensohn, J. (2011). Asymmetries in gender and number agreement processing in late bilinguals. In L. A. Ortiz-López (Ed.), $13^{\text {th }}$ Hispanic Linguistics Symposium (pp. 169-177). Somerville, MA: Cascadilla Proceedings Project.

Sagarra, N., \& Herschensohn, J. (2013). Processing of gender and number agreement in late Spanish bilinguals. International Journal of Bilingualism, 17(5), 607-627. DOI: https://doi. org/10.1177/1367006912453810

Steele, S. (1978). The category AUX as a language universal. Universals of human language, 3, 7-45.

Tokowicz, N., \& MacWhinney, B. (2005). Implicit and explicit measures of sensitivity to violations in second language grammar: An event-related potential investigation. Studies in second language acquisition, 27(2), 173-204. DOI: https://doi. org/10.1017/S0272263105050102

Vafaee, P., Suzuki, Y., \& Kachisnke, I. (2017). Validating grammaticality judgment tests: Evidence from two new psycholinguistic measures. Studies in Second Language Acquisition, 39(1), 59-95. DOI: https:// doi.org/10.1017/S0272263116000097

White, L., Valenzuela, E., Kozlowska-Macgregor, M., \& Leung, Y.K. I. (2004). Gender and number agreement in nonnative Spanish. Applied Psycholinguistics, 25(1), 105-133. DOI: https://doi.org/10.1017/ S0142716404001067

Zhang, R. (2013). Investigating linguistic knowledge of a second language and its relationship to general language proficiency and individual learner differences in an EFL context (Unpublished doctoral dissertation). University of Auckland, Auckland, New Zealand. 